\title{
Influence of Decision Responsibility and Consequence on Escalation of Commitment in Corporate Investment
}

\author{
Olus ola I. Akinbobola ${ }^{1, *}$, Be njamin. O. Ehigie ${ }^{2}$ \\ ${ }^{1}$ Department of Behavioural Sciences, Redeemer's University, Mowe, Ogun State, Nigeria \\ ${ }^{2}$ Department of Psy chology, University of Ibadan, Ibadan, Oyo State, Nigeria
}

\begin{abstract}
The study examined decision responsibility (high versus low) and decision consequence (positive versus negative) on escalation of commitment. The study utilized a 2 X 2 factorial experimental design. Participants were 348 Banking and Finance graduate students randomly selected and assigned to four treatment groups. Escalation of Commitment was in two forms: Intent to Escalate Commitment (IEC), measured with a standardized scale and Escalation of Commitment Behaviour (ECB), measured by the amount of money a decision maker is willing to invest in a business scenario. Results of 2 $\mathrm{X} 2$ (ANOVA), revealed that decision responsibility (DR) and decision consequence (DC) had significant main effects on ECB. The interaction effects of both variables showed that ECB was highest under low decision responsibility and positive decision consequence condition. Only decision responsibility had significant main effect on IEC. IEC positively influenced ECB. Importance of decision responsibility has implication for escalation of commitment. It is therefore recommended that management should be tactical in engaging individuals with decision responsibility in decision making involving initial loss.
\end{abstract}

Keywords Decision Responsibility, Decision Consequence, Intent to Escalate Commitment, Escalation of Commitment Behaviour

\section{Introduction}

In the course of decision making, it is often observed that organisations continue to invest in their original course of action even after receiving substantial negative information concerning it. An important organisational context in which organisations may take concrete actions to justify their original decision following negative feedback is that of investment decision making.

Commitment to investment decision is when resources are allocated to a course of action and in which the level of resources can be increased at the discretion of the decision maker. Within investment decision context, negative feedback may actually cause the organisation to increase the commitment of resources. An increase in commitment of resources to a previous investment decision, in spite of negative feedback, is escalation of commitment.

Escalation of commitment is an irrational commitment of increased resources to investment decision to bring about rationality to the in itial decision[1].

The introduction of Structural Adjustment Programme (SAP) in countries such as Nigeria in 1985 led to the liberalisation of the banking license and the deregulation of

\footnotetext{
* Corresponding author:

solaakinbobola@yahoo.co.uk (Olusola I. Akinbobola)

Published online at http://journal.sapub.org/ijap

Copyright (C) 2012 Scientific \& Academic Publishing. All Rights Reserved
}

the economy. However, in the early 1990's clear signs of distress started to emerge in the financial institution especially banks, probably due to increased and heightened competition from the new banks[2-4]. Distress in financial institutions may be tied to escalation of commitment[5]. Organisations including financial institution exhibit escalation of commitment in some decisions and may become locked unto escalation situation. This type of situation is called "syndrome of decision error"[6]. This unwarranted persistence with a losing course of action could be avoided if a change in the course of action was instituted. Continued investment in a losing course of action may lead to great losses.

Escalation of commitment may be explained in terms of behaviour such as amount of money invested in a losing course of action[1]. However, in literature it has been argued that behaviours are preceded by intentions. In the postulations of theory of reasoned action[7] and theory of planned behaviour[8] behavioural intent was posited to be the most important predictor of behaviour which suggest, therefore, that intention to escalate can be relevant.

Every escalation situation concerns at least two decisions, the initial decision and a subsequent decision to stick to the initial course of action. Certain psychological factors have been imp licated to cause escalation of commitment. So me of these are decision responsibility and decision consequence. Staw postulated that the interaction of decision responsibility and decision consequence is a necessary condition to infer self-justification for escalation of commitment. Individuals 
may be placed with the decision responsibility of allocating resources to a course of action in an investment decision context.

The individuals with personal responsibility for a decision may be saddled with the subsequent outcome which is the decision consequence that resulted from the allocation of resources to that course of action. Therefore they escalate in order to justify prior decision and to de monstrate the ultimate rationality of a losing course of action. Justification theory[1] and self-perception theory[9] posited that individuals restore rationality to their own behaviour. Self-perception theory suggested further that individuals avoid the self causality to negative consequences which cannot be attributed to an external source.

It is presumed that having the decision responsibility to freely make the initial decision on a course of action that subsequently produced a negative decision consequence, decision makers felt personally responsible for the outcome. They escalate commitment in an effort to justify to self for ego defense and justify to others for public justification. The escalation problem has been characterized as being born by the decision responsibility of the decision maker on the initial decision and the decision consequence especially when such outcome is unfavourable.

Res earchers like[10-12], manipulated personal responsibi lity for initial decision and found that high personal responsibility increased escalation of commitment.[13] in a replication of Staw's experiment revealed that there is no escalation of commitment following negative feedback. [14],[15] reiterated that escalation is not a universal reaction to a failed investment decision. In a laboratory study[16-18] revealed that high responsibility individuals reduce their commitment to previously chosen courses of action rather than escalate following negative feedback

Researchers[19],[20] revealed that responsibility for decision consequence induces escalation of commitment. Other researchers[21], revealed that escalation of commitment did not occur in the high involvement group and negative feedback group for tax preparers.[17] found that even though people tend to escalate immediately after negative decision consequence, this tendency reversed over time. Furthermore,[22] reported that the more negative feedback in the early stages of a course of action, the greater the propensity of the decision maker to withdraw.

The escalation of commitment makes it difficult for people to evaluate the outcomes of their decisions. The decision maker does not consider other options but sticks to an initial decision which resulted in negative decision consequence. This situation may adversely affect the investment fortunes of the financial institutions leading to distress of such financial institutions. This obvious lapse has prompted this study. There has been a dearth of research on the influence on decision responsibility and decision consequence on intent to escalate commitment in general, and on escalation of commitment behaviour specifically in Nigeria.
Based on the foregoing, the present study sought to empirically compare intent to escalate commitment and the escalation of commitment behaviour of those who receive high decision responsibility and those who receive low decision responsibility. The present study will also examine the predictive ability of intent to escalate commitment on escalation of commit ment behaviour.

The hypotheses stated are:

1. There will be significant independent and joint effects of decision responsibility and decision consequence on intent to escalate commitment

2. There will be significant independent and joint effects of decision responsibility and decision consequence on escalation of commitment behaviour.

3. Intent to escalate commitment will positively predict escalation of commitment behaviour.

\section{Method}

\subsection{Research Design}

An experimental research was conducted, using a 2 X 2 factorial design. The independent variables in the design are decision responsibility (high versus low) and decision consequence (positive versus negative). Generally, the dependent variables are intent to escalate of commitment (IEC) and escalation of commitment behaviour (ECB).

\subsection{Participants}

A total of 348 participants who are Master of Business Administration (Banking and Finance) students of a University also took part in the main study. In the main study, $210(60.3 \%)$ male and (138) (39.7\%) female participated in the study. Their average age was 37.62 with standard deviation of 6.16. Tenure on the job had an average of 11.36 and standard deviation of 6.14. The participants were working with (185) (53.2\%) in banking, (26) $(7.5 \%)$ participants in other financial institutions, (115) $(33.0 \%)$ participants in finance and accounts departments of non-financial organisations and $22(6.3 \%)$ in related departments. In line with[23] pattern of study.

Each participant was randomly assigned into one of 4 treatment groups. High decision responsibility and positive decision consequence treatment group comprised of 88 participants with $55(60.50 \%)$ male and $33(37.50 \%)$ female. High decision responsibility and negative decision cons equence treatment group was made up of 86 participants with $54(67.79 \%)$ male and $32(37.21 \%)$ female. Low decision responsibility and positive decision consequence treatment group comprised of 90 participants with 52 $(57.78 \%)$ male and $38(42.22 \%)$ female. Low decision responsibility and negative decision consequence treatment group had 84 participants comprising of $49(58.34 \%)$ male and $35(41.66 \%)$ female.

\subsection{Instruments}


The intent to escalate commitment (IEC) scale is constructed for the purpose of this study. The scale is composed of 27 items Likert format and rated as Strongly Agree (5) to Strongly Disagree (1). Higher values in the IEC scale reflect higher intention to escalate commitment. It originally had 34 items that described the extent of intent to escalate commitment, in terms of predisposition and tendency to stick to an initial course of action despite convincing proofs received from negative feedback that the initial decision was effective. The 34 items were given to some psychologists as experts for content validation following[24]. The experts were requested to indicate whether or not they considered each item as measuring intent to escalate commitment using a 5-point Likert type response ranging from Strongly Disagree (1) to Strongly Agree (5). Out of the 34 items, 27 items that were above the average score of 3 were accepted as valid.

The 27 items were subjected to item-total correlation. The items with coefficient that ranged between 0.37 and 0.94 were retained[25]. The reliability for the scale is coefficient alpha of 0.97 The 27 items were subjected to factor analys is using the varimax rotation leading to three factors accounting for $71.9 \%$ of the total variance. Based on literature[1],[23], the three factors were named external justification, ego defense and biased belief update. The coefficient alpha for the three factors are: $0.97,0.96$ and 0.84 respectively.

Escalation of commitment behaviour is measured in an experimental study and utilised scenario for investment decision developed by Staw (1976). The scenario comprised the first investment decision and the second investment decision where the independent variables decision responsibility (high versus low) and decision consequence (positive and negative) were manipulated. There are 4 treatment conditions of investment decisions following the 2 $\mathrm{X} 2$ factorial design. Escalation of commitment behaviour is measured as the difference between the amount of money initially invested to a unit and the amount invested after feedback on the outcome of in itial investment. It is obtained by subtracting the amount invested on the first investment decision (a constant) fro $m$ the a mount invested on the second investment decision. A positive score is obtained when the investment amount at first decision is lower than the investment amount on second decision. A negative score is obtained when the investment amount at first decision is higher than the investment amount on second decision. A positive score indicates escalation of commitment. A negative score indicates de-escalation of commitment.

For manipulative check of variables, dec is ionres ponsibili ty was measured with one item 7-point bipolar adjective scale. Participants indicated the extent to which they felt responsible for the first and second decision. The bipolar adjectives ranged between low responsibility to high responsibility. Decision consequence was measured with a one item 7- point bipolar adjective scale. Participants indicated their perception of the first investment decision outcome. The bipolar adjectives ranged between negative consequence to positive cons equence.

\subsection{Proce dure}

Prospective participants were drawn from the class list using systematic random sampling. This grouping was done separately for males and females. The experiment took place in the auditorium. The participants were willing and were assured of confidentiality.

All the participants were presented with a prior ten-year financial condition of A \& S Company from 1987 to 1997. The first investment decision in which the participants made an initial dec ision to allocate ten (10) million naira Research and Development ( $R$ and $D$ ) funds to either of two corporate divisions (consumer or industrial).

In decision responsibility treatment, participants in high decision responsibility condition sequentially made two investment decisions. After making the first investment decision, only high decision responsibility participants were asked to write a paragraph to defend the allocation. In low decision responsibility condition, half of the total participants under this treatment were made to receive investment decision for consumer division while the other half received for industrial div ision. Participants were made to understand that another financial executive of the company had made an earlier Research and Development funding decision in 1997 and had decided to invest all the Research and Development ( $R$ and D) funds in either the consumer or industrial corporate divisions. Participants in the low decision responsibility condition made only a second decision without having made a prior choice as to which corporate division was most deserving of the $\mathrm{R}$ and $\mathrm{D}$ funds.

In decision consequence treatment, half of the total participants under this treatment were made to receive investment decision for positive consequence condition while the other half received for negative consequence condition. In the positive decision consequence condition, participants received financial data, which showed that the chosen corporate division had returned to profitable levels while the unchosen corporate division continued to decline. In a parallel manner, participants in the negative decision consequence condition received financial data, which showed a deepening decline in the profitability of the chosen corporate division but an improvement in the unchosen corporate division.

All the participants were presented with a five-year financialcondition of A \& S Company from 1998 to 2002. In the second investment decision, another twenty (20) million naira Research and Development ( $R$ and $D$ ) funds was made available to be shared between the two corporate divisions. The participants were required to write their responses specifying the amount of money they would allocate to the two corporate divisions. After the second investment decision the participants were asked to write a paragraph to defend their decision. 


\section{Results}

Table 1. Bivariate correlation between IEC, 3 subscales (external justification, ego defense and biased belief update) and ECB

\begin{tabular}{|cccccc|}
\hline Variable & Mean & SD & $\mathrm{df}$ & $\mathrm{r}$ & $\mathrm{p}$ \\
IEC & 90.09 & 23.21 & 343 & .39 & $<.01$ \\
ECB & 1.37 & .48 & & & \\
External Justification & 43.43 & 15.44 & & & \\
ECB & 1.37 & .48 & 343 & .25 & $<.01$ \\
& & & & & \\
Ego Defense & 30.51 & 10.14 & & & \\
ECB & 1.37 & .48 & 343 & .20 & $<.01$ \\
Biased Belief Update & 19.05 & 6.82 & & & \\
ECB & 1.37 & .48 & 343 & .17 & $<.01$ \\
\hline
\end{tabular}

Table 2. 2x2 ANOVA showing the main and interact ion effects of decision responsibility (DR) and decision consequence (DC) on IEC, 3 subscales (external justification EJ, ego defense ED, biased belief update BBU) and ECB

\begin{tabular}{|c|c|c|c|c|c|c|}
\hline \multirow[t]{2}{*}{ DV } & $\begin{array}{c}\text { Variabl } \\
\mathrm{e}\end{array}$ & $\begin{array}{c}\text { Sum of } \\
\text { Squares }\end{array}$ & Df & $\begin{array}{l}\text { Mean } \\
\text { Square }\end{array}$ & $\mathrm{F}$ & $\mathrm{P}$ \\
\hline & DR & 10463.95 & 1 & 10463.95 & 20.46 & $<.01$ \\
\hline \multirow[t]{4}{*}{ IEC } & DC & .37 & 1 & .37 & .01 & n.s \\
\hline & $\begin{array}{c}\mathrm{DR} x \\
\text { DC }\end{array}$ & 8.43 & 1 & 8.43 & .02 & n.s \\
\hline & Error & $\begin{array}{c}176407.1 \\
7\end{array}$ & 344 & 512.81 & & \\
\hline & Total & $\begin{array}{c}186879.9 \\
2\end{array}$ & 347 & & & \\
\hline \multirow[t]{5}{*}{ EJ } & DR & 5338.33 & 1 & 5338.33 & 23.77 & $<.01$ \\
\hline & $\mathrm{DC}$ & 7.21 & 1 & 7.21 & .32 & n.s \\
\hline & $\begin{array}{c}\text { DR x } \\
\text { DC }\end{array}$ & 92.97 & 1 & 92.97 & .41 & n.s \\
\hline & Error & 77245.47 & 344 & 224.55 & & \\
\hline & Total & 82683.98 & 347 & & & \\
\hline \multirow[t]{5}{*}{ ED } & DR & 1915.84 & 1 & 1915.84 & 19.54 & $<.01$ \\
\hline & DC & 18.14 & 1 & 18.14 & .19 & n.s \\
\hline & $\begin{array}{l}\mathrm{DR} x \\
\mathrm{DC}\end{array}$ & $\begin{array}{c}7.705 \mathrm{E}-0 \\
2\end{array}$ & 1 & $\begin{array}{c}7.705 \mathrm{E}-0 \\
2\end{array}$ & .00 & n.s \\
\hline & Error & 33723.39 & 344 & 98.03 & & \\
\hline & Total & 35665.07 & 347 & & & \\
\hline \multirow[t]{5}{*}{$\begin{array}{l}\mathrm{BB} \\
\mathrm{U}\end{array}$} & DR & 884.31 & 1 & 884.31 & 19.94 & $<.01$ \\
\hline & $\mathrm{DC}$ & $\begin{array}{c}3.066 \mathrm{E}-0 \\
2\end{array}$ & 1 & $\begin{array}{c}3.066 \mathrm{E}-0 \\
2\end{array}$ & .00 & n.s \\
\hline & $\begin{array}{c}\mathrm{DR} x \\
\text { DC }\end{array}$ & 5.83 & 1 & 5.83 & .13 & n.s \\
\hline & Error & 15253.08 & 344 & 44.34 & & \\
\hline & Total & 16146.28 & 347 & & & \\
\hline \multirow[t]{5}{*}{$\begin{array}{c}\text { EC } \\
\text { B }\end{array}$} & DR & 5.843 & 1 & 5.843 & 28.68 & $<.01$ \\
\hline & $\mathrm{DC}$ & 3.430 & 1 & 3.430 & 16.84 & $<.01$ \\
\hline & $\begin{array}{c}\text { DR x } \\
\text { DC }\end{array}$ & 1.328 & 1 & 1.328 & 6.52 & $<.01$ \\
\hline & Error & 70.083 & 344 & .204 & & \\
\hline & Total & 80.684 & 347 & & & \\
\hline
\end{tabular}

Intent to escalate commitment was measured as a composite of the score on its three subscales which are external justification, ego defense and biased belief update.

A justification for the use of composite score is observed in Table 1 where the three subscales are significantly intercorrelated and each correlates significantly with intent to escalate commitment, as can be seen in the correlation matrix.

Two-way Analysis of variance was employed to test the first two hypotheses. The result in Table 2 reveals main and interaction effects of the independent variables. Result in Table 3 reveals mean values of interaction between the independent variables. In hypothesis 1, the results reveal significant main effects of only decision responsibility on intent to escalate commitment $(\mathrm{F}(1,344)=20.46, \mathrm{p}<.01)$. The result reveals that participants in low decision responsibility are significantly higher on intent to escalate commitment ( $\bar{x}=95.22$ ) than high decision responsibility participants $(\bar{x}=84.22)$.

Table 3. Mean values of interact ion between decision responsibility and decision consequence on IEC, 3 subscales (external justification EJ, ego defense ED, biased belief update BBU) and ECB

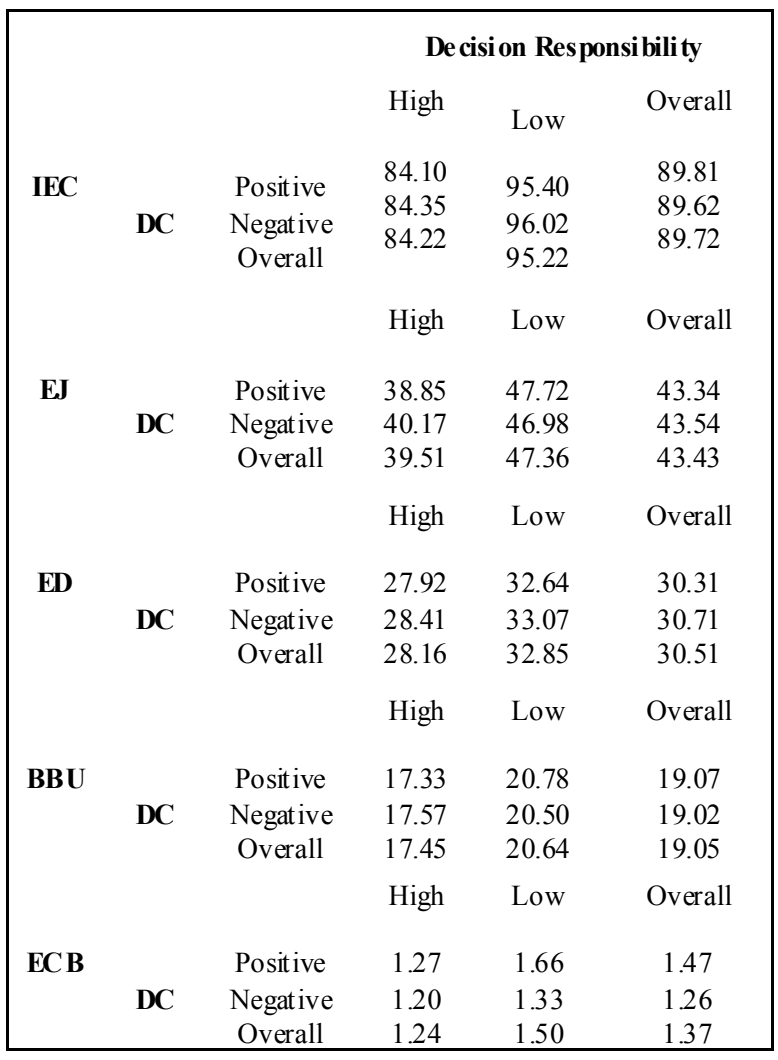

Other serendipitous findings were made on the main and interaction effects of decision responsibility and decision consequence on the three subscales of intent to escalate commitment. There is a significant main effect of decision responsibility on external justification for escalation of commitment $(\mathrm{F}(1,344)=23.77, \mathrm{p}<.01)$.

Participants in low decision responsibility are significantly higher on external justification for escalation of commitment ( $\bar{x}=47.36$ ) than high decision responsibility participants $(\bar{x}=39.51)$. The results also reveals significant main effects of decision responsibility on ego defense for escalation of commitment $(\mathrm{F}(1,344)=19.54, \mathrm{p}<.01)$. Participants in low decision responsibility are significantly higher on ego defense for escalation of commitment $(\bar{x}=$ $32.85)$ than high decision responsibility participants $(\bar{x}=$ 
28.16). The result further reveals significant main effect of decision responsibility on biased belief update for escalation of commit ment. $(\mathrm{F}(1,344)=19.94, \mathrm{p}<.01)$. Participants in low decision responsibility are significantly higher on biased belief update for escalation of co mmit ment ( $\bar{x}=20.64)$ than high decision responsibility participants $(\bar{x}=17.45)$. The hypothesis is not confirmed.

In hypothesis 2 , the result of the $2 \mathrm{X} 2 \mathrm{~A}$ NOVA on Tab le 2 reveals significant main effect of decision responsibility on escalation of commitment behaviour $(\mathrm{F}(1,344)=28.68$, $\mathrm{P}$ $<.01)$. Participants in low decision responsibility are significantly higher on escalation of commitment behaviour $(\bar{x}=1.50)$ than high decision responsibility participants $(\bar{x}$ $=1.24)$ (see Table 3$)$.

The result of the 2 X 2 ANOVA shown in Table 2 reveals significant main effect of decision consequence on escalation of commitment behaviour $(\mathrm{F}(1,344)=16.84, \mathrm{P}<.01)$. Participants in positive decision consequence condition were significantly higher on escalation of commitment behaviour $(\bar{x}=1.47)$ than negative decision consequence participants $(\bar{x}=1.26)$. The $2 \times 2$ ANOVA result further shows significant interaction effect of decision responsibility and decision consequence on escalation of commitment behaviour, $(\mathrm{F}(1,344)=6.52, \mathrm{P}<.01)$.

A multiple comparison analysis test using Scheffe's analysis in table 4 reveals that escalation of commitment behaviour is significantly higher amongst participants that received low decision responsibility and positive decision consequence $(\bar{x}=1.66)$ than those that received high decision responsibility and positive decision consequence $(\bar{x}=1.27)$, high decision responsibility and negative decision consequence $(\bar{x}=1.20)$ and, low decision responsibility and negative decision consequence $(\bar{x}=1.33)$. The hypothesis is not confirmed.

However, other serendipitous results show that there was no significant difference among other paired comparisons which are high decision responsibility and positive decision consequence, high decision responsibility and negative decision consequence, low decision responsibility and negative decision consequence.

Table 4. Summary of Scheffe's multiple comparison analysis showing group differences involving DR (high/low) and DC (positive/negative) on escalation of commitment behaviour

\begin{tabular}{|ccccccc|}
\hline & Groups & N & Mean & 2 & 3 & 4 \\
1 & High DR/Positive DC & 88 & 1.27 & & & \\
2 & High Dr/Negative DC & 86 & 1.20 & & $-0.23^{*}$ & -0.23 \\
& & & & 0.23 & & -0.23 \\
3 & Low DR/Positive DC & 90 & 1.66 & & $-0.23^{*}$ & \\
4 & Low DR/Negative DC & 84 & 1.33 & & & $-0.23^{*}$ \\
\hline
\end{tabular}

In addition, the interaction between dec ision responsibility and decision consequence is depicted graphically in Fig. 1. It can be observed that escalation of commitment behaviour is higher for low decision responsibility than high decision responsibility under both positive and negative consequence situations. However, the difference between low decision responsibility and high decision responsibility is higher under positive decision consequence than under negative decision consequence as can be observed in the sloppiness of the curve.

In hypothesis three, the result in Table 5 reveals that intent to escalate commitment positively predicts escalation of commitment behaviour $\mathrm{F}(1,346)=63.22 ; \mathrm{B}=0.39 ; \mathrm{P}<.01)$. Participants who exhibit intention to escalate commitment also exhibit escalation of commitment behaviour. The hypothesis is confirmed.

Table 5. Standard regression of intent to escalate commitment on escalation of commitment behavior

\begin{tabular}{|ccccccccc|}
\hline $\begin{array}{c}\text { Vari } \\
\text { able }\end{array}$ & $\begin{array}{c}\text { Sum of } \\
\text { squares }\end{array}$ & df & $\begin{array}{c}\text { Mean } \\
\text { Square }\end{array}$ & F & $\begin{array}{c}\text { Bet } \\
\text { a }\end{array}$ & t & P \\
IEC & 12.50 & $\begin{array}{c}1 / 34 \\
6\end{array}$ & 12.50 & 63.2 & $\begin{array}{c}0.3 \\
9\end{array}$ & 8.00 & $<.01$ \\
\hline
\end{tabular}

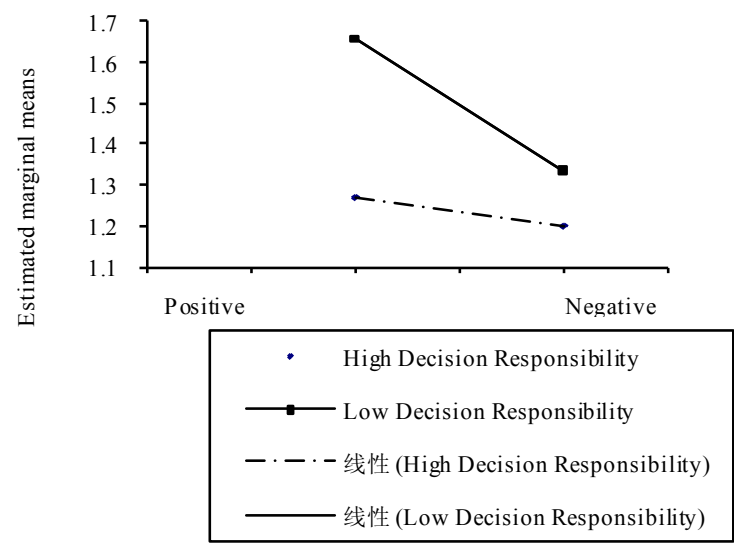

Figure 1. Interaction between decision responsibility and decision Consequence on escalation of commitment behavior

\section{Conclusions}

\subsection{Discussion and Implication of Findings}

In hypothesis one the result revealed significant main effect of decision responsibility on intent to escalate commitment and on each of the three subscales which are external justification, ego defense and biased belief update. The hypothesis is not confirmed for intent to escalate commitment and the three sub scales. Those low in decision responsibility escalate commitment more than those high in decision responsibility. This result supported those of some other researchers such as[17];[18] where high personal responsibility group reduced escalating commitment. The result did not supporting other researchers like,[10-12] who manipulated personal responsibility for initial decision and found that high personal responsibility increased escalation of commitment.

There is no significant main effect of decision consequence on intent to escalate commitment and its three subscales which are external justification, ego defense and biased belief update.[13] in a replication of Staw's 
experiment revealed that there is no escalation of commitment following negative feedback.[14];[15] reiterated that escalation is not a universal reaction to a failed investment decision.

Contrary to expectation, there is no significant interaction effect of decision responsibility and decision consequence on intent to escalate commitment and its three sub scales which are external justification, ego defense and biased belief update. This result supported prior review e.g.[21] which revealed that escalation of commitment did not occur in the high involvement group and negative feedback group for tax preparers.

The hypothesis two was not confirmed as participants in low decision responsibility are significantly higher on escalation of commitment behaviour than high decision responsibility participants. The result obtained is consistent with the results obtained in a laboratory study by[16]. They revealed that high responsibility individuals reduce their commitment to previously chosen courses of action rather than escalate following negative feedback.

Participants in positive decision consequence were significantly higher on escalation of commitment behaviour than negative decision consequence participants. The result confirmed previous studies,[17] found that even though people tend to escalate immediately after negative decision consequence, this tendency reversed over time. Other researchers [22] reported that the more negative feedback in the early stages of a course of action, the greater the propensity of the decision maker to withdraw.

There was a significant interaction effect of decision responsibility and decision consequence on escalation of commitment behaviour. A multiple comparison analysis of mean scores revealed that escalation of commitment behaviour is significantly higher amongst participants that received low decision responsibility and positive decision consequence than those that received high decision responsibility and positive decision consequence, high decision responsibility and negative decision consequence, and low decision responsibility and negative decision consequence. The hypothesis is not confirmed.

The assumption of[1] justification theory reiterated that decision makers with high decision responsibility and negative decision consequence escalate commitment to a losing course of action. However, unlike in earlier research, findings from the present study suggest that neither high decision responsibility nor negative decision consequence are necessary conditions for escalation of commitment to occur. Some researchers [19]; [20] revealed that responsibilit $\mathrm{y}$ for decision consequence induces escalation of commitment.[19] found that escalation of commitment also occurred for individuals in the negative consequence group and those in the positive consequence group.

Result of the qualitative report highlighted other reasons why the participants increase or decrease commitment of resources to investment decision. Commitment of resources was based on some reasons such as the functions of the products to the end users. Some participants' commitment was based on the previous year's financial performances of the two divisions and the consequences of loss or profit indicating that the value of the allocation determined proportion of turnover. Other participants committed resources to the division in loss position after the initial allocation in order to resuscitate performance and improve earnings of the division because it was unwise to totally ignore a business in existence that is distressed. They therefore strategically motivated the division by increasing commitment of resources. The findings of the qualitative report may be the probable reason why the result of hypothesis one and hypothesis two though significant, did not support previous study by[1].

In hypothes is three, results revealed that intent to escalate commitment positively influences escalation of commitment behavior. Participants' intention to escalate commitment accurately predicted their actual escalation of commitment behaviour. The result is supported by the postulation of [7] in theory of reasoned action and[8] in theory of planned behaviour that behavioural intent is the most important predictor of behaviour.

\subsection{Implication and Recommendation}

The study identified that decision responsibility and decision consequence influence both intent to escalate of commitment and escalation of commitment behaviour. The report that intent to escalate commitment predicts escalation of commitment behaviour is confirmed by literature.

With the result obtained from the research management should endorse rational decision making in staff especially those staff who have high intent to escalate commitment so as to cub them from exhibiting the actual escalation of commitment behaviour.

The present study used laboratory experiment with fictitious scenarios. This is not peculiar to the present study alone but is general to all laboratory experiment. Future studies should use field experiment and or longitudinal study to collect corporate data to further ass ess the generalis ability of the findings and a longer period of study.

\section{REFERENCES}

[1] Staw, B. M. Knee-deep in the big muddy: A study of escalating commitment to a chosen course of action. Organisational Behaviour and Human Performance, vol. 16, pp. $27-44,(1976)$.

[2] Alashi, S. O. Banking crisis: It's causes, early warning signals and resolution. Conference proceedings: Enhancing financial sector soundness in Nigeria, Central Bank of Nigeria's second monetary policy conference, Abuja, (2002).

[3] Ekpenyong, D. B. The financial sector Nigerian grant. In I. A., Adelemo \& J. M. Baba (Eds.) Tropics. Gabimo PublishingCo. Ltd. Lagos, (1993).

[4] World Bank Nigeria's structural adjustment program, policies, implementation and impact, West African 
department country operations division 12366, (1993).

[5] Kreitner, R., \& Kinicki, A. Organisational behavior. Irwin McGraw-Hill, Boston, (2000).

[6] Staw, B. M. The escalation of commitment of a course of action. Academy of Management Review vol. 6, pp. 577-587, (1981).

[7] Fishbein, M. \& Ajzen, I. Belief, attitude, intention and behaviour. Reading, Addison-Wesley, MA, (1975).

[8] Ajzen, I. Attitudes, personality and behaviour. The Dorsey Press Chicago, (1998).

[9] Bems, D. J. Self-perception theory. In I., Berkowitz (Ed.) Advances in experimental social psychology. New York: Academic Press, (pp.6), (1972).

[10] Bazerman, M. H., Giuliano \& Appelman Escalation of commitment in individual and group decision making. Organisational Behaviour and Human Performance, vol. 3 no. 2, pp. 141-152, (1984).

[11] Schmidt, J. B. \& Calantone, R. J. Escalation of commitment during new product development. Journal of the Academy of Marketing Science vol. 3 no. 2, pp. 103-118, (2002).

[12] Whyte, G. Diffusion of responsibility: Effects on the escalation tendency. Journal of Applied Psychology, vol. 76, no. 3, pp. 408-415, (1991).

[13] Singer, M. S., \& Singer, A. E. Is there always escalation of commitment? Psychological Reports, vol. 5, no. 3, pp. 816-818, (1985).

[14] Armstrong, J.S., Coville, N. \& Safranek B. Escalation bias: Does it extend marketing? Journal of the Academy of Marketing Science vol. 21, pp. 247-253, (1993).

[15] Singer, M. S. Individual differences in adaptation-innovation and the escalation of commitment paradigm. The Journal of Social Psychology vol. 130, 561-563, (1990).
[16] Singer, M. S., \& Singer, A. E. Individual differences and escalation of commitment paradigm. Journal of Social Psychology, vol. 126, no.2, pp.197-204, (1986).

[17] McCain, B.E. Continuing investment under conditions of failure: A laboratory study of limits to escalation. Journal of Applied Psychology, vol. 71, pp.280-284, (1986).

[18] Goltz, S. M. A sequential learning analysis of decisions in organisations to escalate investments despite continuing costs or losses. Journal of Applied Behavioral Analysis, vol. 25, pp. 561-574, (1992).

[19] Schoorman, F. D., \& Holahan, P. J. Psychological antecedents of escalation behavior: Effects of choice, responsibility, and decision consequences. Journal of Applied Psychology, vol. 81, pp. 786 - 794, (1996).

[20] Ruchala, L. V., Hill, J. W., and Dalton, D. Escalation and the diffusion of responsibility: a commercial lend ing experiment. Journal of Business Research, vol. 37 no. 1, pp. 15-26, (1996).

[21] Brody, R.G., \& Lowe, D. J. Escalation of commitment in professional tax preparers. Psychological Reports, vol. 7, no. 1, pp. 339-344, (1995).

[22] Garland, H.C., Sandefur, A., \& Rogers, A. C. De-escalation of commitment in oil exploration when sunk cost and negative feedback coincide. Journal of Applied Psychology, vol., 75, no. 6, pp. 721-727, (1990).

[23] Biyalagorsky, D., Boulding, W., \& Staelin, R. Stuck in the past: Why organisations exhibit escalation bias. Organisational behavior and human decision process under Review. Retrieved January 3, 2004 online Available: http// www.google.com, (2001).

[24] Nunnally, J. C. 1967. Psychometric Theory, McGraw-Hill, New York.

[25] Rust, J., \& Golombok, S. (1995) Modern Psychometric: The Science of Psychological Assessment. New York. Routledge. 